\title{
Flow line variations in abyssal hill morphology for the Pacific-Antarctic Ridge at $65^{\circ} \mathrm{S}$
}

\author{
Ana Macario, ${ }^{1,2}$ William F. Haxby, ${ }^{1}$ John A. Goff, ${ }^{3}$ William B. F. Ryan, ${ }^{1}$ \\ Steve C. Cande, ${ }^{4}$ and Carol A. Raymond ${ }^{5}$
}

\begin{abstract}
We present the results of a statistical study on the morphological characteristics of abyssal hills recently mapped along two adjacent segments of the Pacific-Antarctic Ridge at $65^{\circ} \mathrm{S}$. The studied area is a densely surveyed corridor $(60 \mathrm{~km}$ wide by $600 \mathrm{~km}$ long) which is centered on the Pitman Fracture Zone (PFZ) and extends to 12 Ma crust on both sides of the ridge. Abyssal hill size parameters (RMS height $H$ and characteristic width $\lambda$ ) are estimated using Hydrosweep multibeam data. Variations in abyssal hill characteristics are compared with spreading rate history and crustal structure (as inferred from the mantle Bouguer gravity) in order to indirectly quantify the evolution of this ridge crest system. The magnetic data document an abrupt acceleration in spreading rate from $\sim 36$ to $-63 \mathrm{~mm} / \mathrm{yr}$ (full rate) at Chron 3a (5.7-6.4 Ma). Our results indicate a statistically significant negative correlation between abyssal hill size parameters and full spreading rates. Abyssal hills formed during the slower spreading period (ages >8 Ma; full rates $36-44 \mathrm{~mm} / \mathrm{yr}$ ) are $31-86 \%$ taller and $21->100 \%$ wider than hills created during the faster spreading interval (ages $<4 \mathrm{Ma}$; full rates $52-63 \mathrm{~mm} / \mathrm{yr}$ ). The well-resolved positive correlation between $H$ and $\lambda$ is interpreted as an indication of temporal changes in the flexural rigidity of the lithosphere near the vicinity of the ridge crest and, by implication, axial thermal structure. However, we cannot rule out that such positive trend is due to constructional volcanism. The lack of correlation between crustal thickness and abyssal hill size parameters is likely to be caused by the small magnitude of crustal thickness variations along flow lines $(-0.4$ $\mathrm{km}$ in contrast to $\sim 2 \mathrm{~km}$ reported in previous studies for the Mid-Atlantic Ridge). The most significant variations in crustal thickness are seen across the PFZ (thinning from north to south by $0.5-0.7 \mathrm{~km}$ ), which coincide with a well-resolved increase in the averaged $\lambda$ estimate. The predictions of the detachment surface model in terms of morphological and structural inside/outside comer asymmetries are not supported by our observations. The main variations in $H$ and $\lambda$ that cannot be explained in terms of either the spreading rate or crustal thickness effect include the following: (1) anomalously large abyssal hills north of the PFZ for 4-6 Ma age crust; (2) abyssal hill size estimates for crustal ages greater than 8 Ma show significant asymmetry for opposite ridge flanks north of the PFZ; and (3) toward the segment ends, $H$ estimates are $27-68 \%$ larger, while $\lambda$ estimates either do not significantly change (to the north of the PFZ) or are up to $40 \%$ smaller (to the south of the PFZ). We suggest that the $H$ and $\lambda$ changes seen toward the segment ends are related to either an increase in the amount of extension (without a corresponding increase in the strength of the lithosphere) or variations in the relative contribution of constructional volcanism to overall abyssal hill morphology.
\end{abstract}

\section{Introduction}

Abyssal hills are created at divergent plate boundaries by a complex combination of extensional tectonics (normal faulting) and volcanism. Although modified by off-axis volcanism, sedimentation, and mass wasting, they represent an indirect record of the complex dynamics of mid-ocean ridge processes. Volcanism contributes to seafloor relief by either creating constructional edifices (typically at slow spreading ridges [e.g., Lewis, 1979; Kappel and Ryan, 1986; Kong et

\footnotetext{
${ }^{1}$ Lamont-Doherty Earth Observatory, Palisades, New York.

${ }^{2}$ Also at Department of Geology, Columbia University, New York.

${ }^{3}$ University of Texas Institute for Geophysics, Austin.

${ }^{4}$ Scripps Institution of Oceanography, La Jolla, Califomia.

5 Jet Propulsion Laboratory, California Institute of Technology, Pasadena.
}

Copyright 1994 by the American Geophysical Union.

Paper number 94JB01409.

0148-0227/94/94JB-01409505.00 ai., 1988; Pockalny et al., 1988; Smith and Cann, 1990]) or by modifying the existing terrain by flooding bathymetric lows or flowing down existing slopes (typically at fast spreading ridges [Keeley et al., 1992]). Alternatively, tectonism contributes to seafloor relief either by vertical (inflation-deflation of the axial magma chamber [e.g., Edwards et al., 1992]) or horizontal (lithospheric extension [e.g., Lonsdale, 1977]) forces which induce abyssal hill formation by normal faulting at both slow and fast spreading ridges [e.g., Rea, 1975; Lonsdale, 1977; Harrison and Stieltjes, 1977; Macdonald and Atwater, 1978; Bicknell et al., 1987; Carbotte and Macdonald, 1991].

Previous studies [e.g., Menard, 1967; Goff, 1991; Hayes and Kane, 1991; Malinverno, 1991; Goff, 1992] have demonstrated a negative correlation between abyssal hill size and the spreading rate (up to $\sim 100 \mathrm{~mm} / \mathrm{yr}$ ) of the mid-ocean ridge at which they were formed. There are two primary postulated causes for this correlation: (1) variations in axial thermal structure as a function of spreading rate [i.e., Goff, 1991]. Cooler lithosphere at slower rates will be able to elastically support larger volcanic loads as well as larger 
normal faults; and (2) the change from axial valley morphology at slower rates to axial high at faster rates at approximately $70 \mathrm{~mm} / \mathrm{yr}$ [Small and Sandwell, 1989]. The axial valley generates large (up to $1 \mathrm{~km}$ throw) inward facing normal faults which, after likely back tilting over adjacent rift mountains, are preserved in the abyssal hill record [i.e., Macdonald, 1982].

Axial thermal structure and morphology are not independent factors. Numerical models for crustal genesis that incorporates hydrothermal cooling and crustal accretion by means of magma lens [Phipps Morgan and Chen, 1993a] have recently confirmed the long-established spreading rate dependence of ridge-axis morphology based on seafloor observations. Phipps Morgan and Chen [1993b] have extended this crustal genesis model to incorporate the effects of variations in the crustal thickness into the heat budget. Their results suggest that the axial thermal structure, which is dependent on both spreading rates and magma input (crustal thickness), is the main control on ridge crest morphology.

A recent geophysical survey centered on the Pitman Fracture Zone PFZ (Ewing cruise 92-1 [Cande et al., 1992; Haxby et al., 1992]) acquired high-resolution bathymetry, gravity, and magnetic data extending to $12 \mathrm{Ma}$ to either side of the PacificAntarctic Ridge flanks at $65^{\circ} \mathrm{S}$ (see Figure 1 for cruise location). The data coverage along the two adjacent ridge segments provides an excellent opportunity to evaluate the dynamical evolution of this intermediate spreading rate ridge as constrained by the abyssal hill record. Over the surveyed portion of the Pacific-Antarctic ridge flanks, spreading rate varies from $\sim 36$ to $\sim 63 \mathrm{~mm} / \mathrm{yr}$ full rate, and crustal thickness changes reach a maximum of $\sim 1 \mathrm{~km}$. Our goal is to provide quantitative observational constraints on the relative dependence of off-axis abyssal hill morphology on these two primary ridge crest variables.

We use the methodology of Goff and Jordan [1988] to characterize the second-order statistics of abyssal hill morphology. The main assumption of their method is that seafloor can be modeled as an approximately homogeneous anisotropic random field defined in part by a parameterized functional form of its covariance function. Secondary processes (off-axis volcanism, sedimentation and mass wasting), which can modify abyssal hill statistics, are assumed to be negligible. We used standard techniques to estimate spreading rate and crustal thickness (as inferred from mantle Bouguer gravity anomalies). Three questions are addressed in this study: (1) What are the systematic flow line variations in abyssal hill morphology?; (2) Are there variations in abyssal hill morphology that cannot be attributed to the spreading rate dependence?; and (3) Does the morphology vary systematically with other indicators of varying axial thermal structure such as crustal thickness?

We first present the results of the statistical characterization study using RMS height $H$ and characteristic width estimates $\lambda$. Flow line variations in $H$ and $\lambda$ are then compared to the spreading rate history and crustal thickness (as inferred from mantle Bouguer gravity anomalies). In general, we find that both $H$ and $\lambda$ are negatively correlated to spreading rate. Flow line variations in crustal thickness are small in magnitude and, for the most part, are not correlated to variations in abyssal hill size parameters. The apparent thinning of the Pacific plate crust from north to south across the PFZ coincides with a well-resolved increase in both $H$ and $\lambda$ for younger crust $(<4 \mathrm{Ma})$. Flow line variations in $\lambda$ estimates over regions of approximately uniform crustal thickness are interpreted as evidence for changes in the lithospheric strength in the vicinity of the ridge crest which imply variations in the axial temperature structure. However, we cannot rule out that some of the flow line variations in $\lambda$ estimates are related to constructional volcanism. Notable exceptions to the abyssal hill size dependence on spreading rate and crustal thickness include the following: (1) anomalously large abyssal hills north of the PFZ for 4-6 Ma age crust; (2) for crustal ages $>8 \mathrm{Ma}$, abyssal hills on the Antarctic plate to north of the PFZ are significantly larger than the ones found on the Pacific plate; and (3) toward the segment ends, $H$ increases, while $\lambda$ either remains the same or decreases.

\section{Pacific-Antarctic Ridge at $65^{\circ} \mathrm{S}$ : Background Information}

The free-air gravity map derived from Geosat/Seasat altimeter data for the studied area and surroundings is shown in Figure 1. The box shows the location of the $60 \mathrm{~km}$ wide by $600 \mathrm{~km}$ long corridor for which we have full Hydrosweep, magnetic and gravity data coverage. The two adjacent segments currently spreading at $\sim 56 \mathrm{~mm} / \mathrm{yr}$ [Cande et al., 1992] are offset by a right-stepping transform $\sim 70 \mathrm{~km}$ long. The transition from a rift valley (south of the PFZ) to an axial high (north of the PFZ) is inferred based on the observed change in the axial gravity signal. The portion of the PacificAntarctic Ridge associated with the rift valley is also characterized by an unusually small subsidence constant relative to global averages [Marks and Stock, 1994].

Plate 1 shows the gridded bathymetry, magnetics and inferred crustal thickness for the densely surveyed area. The procedure for inferring crustal thickness consists of four steps: (1) use Parker's [1973] method to calculate the gravity effect of the gridded topography and the Moho relief (assuming a constant crustal thickness of $6 \mathrm{~km}$; densities for water, crust and mantle material are 1030,2900 , and $3300 \mathrm{~kg} / \mathrm{m}^{3}$ respectively); (2) subtract the model gravity anomalies and gravitational effect of plate cooling with age from the shipborne free-air gravity; (3) grid the residual gravity along track lines to generate the mantle Bouguer gravity anomalies (variations in crustal thickness are assumed to be the source of these anomalies); and (4) downward continuation of the mantle Bouguer gravity anomalies to $7 \mathrm{~km}$ depth in order to obtain crustal thickness variations (a low pass filter with a $25-\mathrm{km}$ wavelength cutoff was applied to reduce high-frequency noise).

In order to facilitate the discussion of the results, we apply the terms "Pacific north" and "Pacific south" to refer to the portion of the Pacific plate situated to the north and south of the PFZ, respectively. A similar terminology is applied to the Antarctic plate. Due to limited data coverage on the Antarctic plate south of the PFZ, we have carried out our analysis only on the portion situated to the north of the PFZ "Antarctic north"). The northern and southern ridge segments overlap by $5 \mathrm{~km}$, and their respective tips are curved toward the transform. This portion of the Pacific-Antarctic Ridge is also characterized by the presence of curved abyssal hill tips only on the outside corners (analogous to "hooked ridges" defined by Tucholke and Shouten [1988]).

The spreading rate history of the study area (Figure 2) is derived from a high-resolution age grid based on magnetic isochrons identified by Cande et al. [1992] and the 


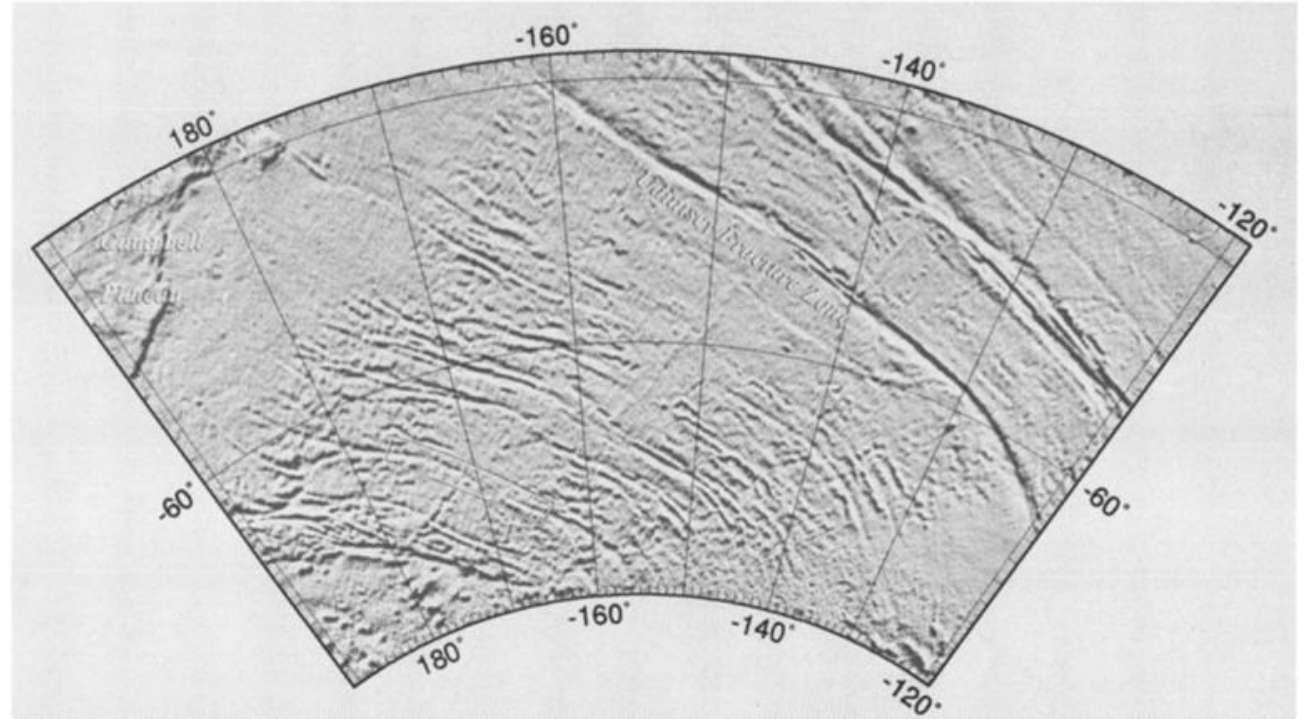

Figure 1. Shaded free-air gravity map derived from satellite altimeter data for the SW Pacific Ocean. The rectangular box denotes the Ewing cruise 92-1 survey limits.

geomagnetic polarity timescale of Cande and Kent [1992]. The most prominent feature of the spreading history is a sharp acceleration in the rate of crustal accretion from $\sim 36$ to $\sim 63$ $\mathrm{mm} / \mathrm{yr}$ (full rate) at Chron 3a (5.7-6.4 Ma) accompanied by a $\sim 10^{\circ}$ clockwise rotation in the strike of abyssal hills. Ridge axis jumps, deduced from a preliminary analysis of bathymetry and magnetic data [Ryan et al., 1992; Haxby et al., 1993], may explain part of the highly variable (both in direction and magnitude) asymmetric spreading history of this ridge.

\section{Stochastic Characterization}

The methodology used to characterize the second-order statistics of abyssal hill morphology and the inversion procedure are presented by Goff and Jordan [1988]. The analyses were performed on three Hydrosweep swaths to the north of the PFZ and two swaths to the south (the farthest ones from the PFZ). Uncertainties in the estimation of some parameters (i.e., fractal dimension and aspect ratio [Goff. 1991]) caused us to focus our analysis on the most robust second-order statistics: (1) RMS height $H$, the average variation of bathymetry about the mean depth; and (2) characteristic width $\lambda$, defined as the width of the covariance function in the normal-to-strike direction. The parameter $\lambda$ visually corresponds the average peak-to-peak distance between the most prominent peaks. Although normal faulting is important in the formation of abyssal hills, $\lambda$ does not necessarily reflect the width of a single-faulted block but rather the average spacing between the main topographic highs or lows.

In order to assure well-resolved abyssal hill size parameters, the swaths of multibeam data used as input must have a length 8-10 times the characteristic abyssal hill width. For intermediate spreading ridges, the characteristic widths range from 3 to $7 \mathrm{~km}$ [Goff, 1991]. In addition, it is essential that the portion of the seafloor to be analyzed consists principally of abyssal hill morphology. In this study we visually identified three areas that do not satisfy this criterion and were therefore excluded from the analyses (Plate 1): (1) a terrain resembling outpouring of off-axis volcanism found on the
Antarctic plate north of the PFZ for crustal ages between 0 and $2 \mathrm{Ma}$; (2) prominent seamounts found on the Pacific plate for crustal ages less than $4 \mathrm{Ma}$; and (3) a large topographic high (bulge) spanning crustal ages between 8 and $10 \mathrm{Ma}$ present on the Pacific plate north of the PFZ that was formed by processes different from the ones related to abyssal hill formation.

A set of fracture zone subparallel lineaments overprinting the abyssal hill fabric is found on the Pacific plate north of the PFZ for crustal ages between 6 and $8 \mathrm{Ma}$ (Plate 1). For this particular terrain, we fixed the orientation of abyssal hill fabric in order to obtain stable $H$ and $\lambda$ estimates. Once the inversion parameters are obtained, the fit of the model covariance to the estimated covariance was systematically used to assess how successfully the parameters were estimated.

The process of choosing the swath segments is unavoidably subjective. Large scarps commonly lead to problematic inversions as they will tend to dominate the covariance function. For example, the scarp at $2 \mathrm{Ma}$ to both sides of the ridge axis north of the PFZ was avoided as it clearly marks the edge of the elevated topography (Figure 3). For the Pacific plate, the scarps associated with the topographic high at 8-10 $\mathrm{Ma}$ and the older edge of the terrain overprinted with subparallel lineaments $(6-8 \mathrm{Ma})$ were also avoided due to unstable inversions (Figure 3). These are thought to be isolated features not representative of normal abyssal hillforming processes. Scarps large enough to cause a significant increase in both $H$ and $\lambda$ values but sufficiently small to yield stable inversion results were not excluded from the analyses. This is the case for the terrain north of the PFZ between 4 and $6 \mathrm{Ma}$ for which we refer to, hereafter, as the locally "anomalous" seafloor (Figure 3).

In addition to identifying and excluding anomalous terrains, we must also choose swath segments which are long enough to resolve parameters, yet short enough to resolve spatial variations (inhomogeneity). The swaths used in this study were divided into $50-80 \mathrm{~km}$ long segments. This limits our temporal resolution at these spreading rates to 1-2 Ma. Most of the swaths used in this study were $-17-40 \mathrm{~km}$ away from the PFZ. In order to investigate the fracture zone influence on abyssal hill morphology, an additional swath analysis was carried out along flow lines adjacent to the PFZ $(-5 \mathrm{~km})$. 


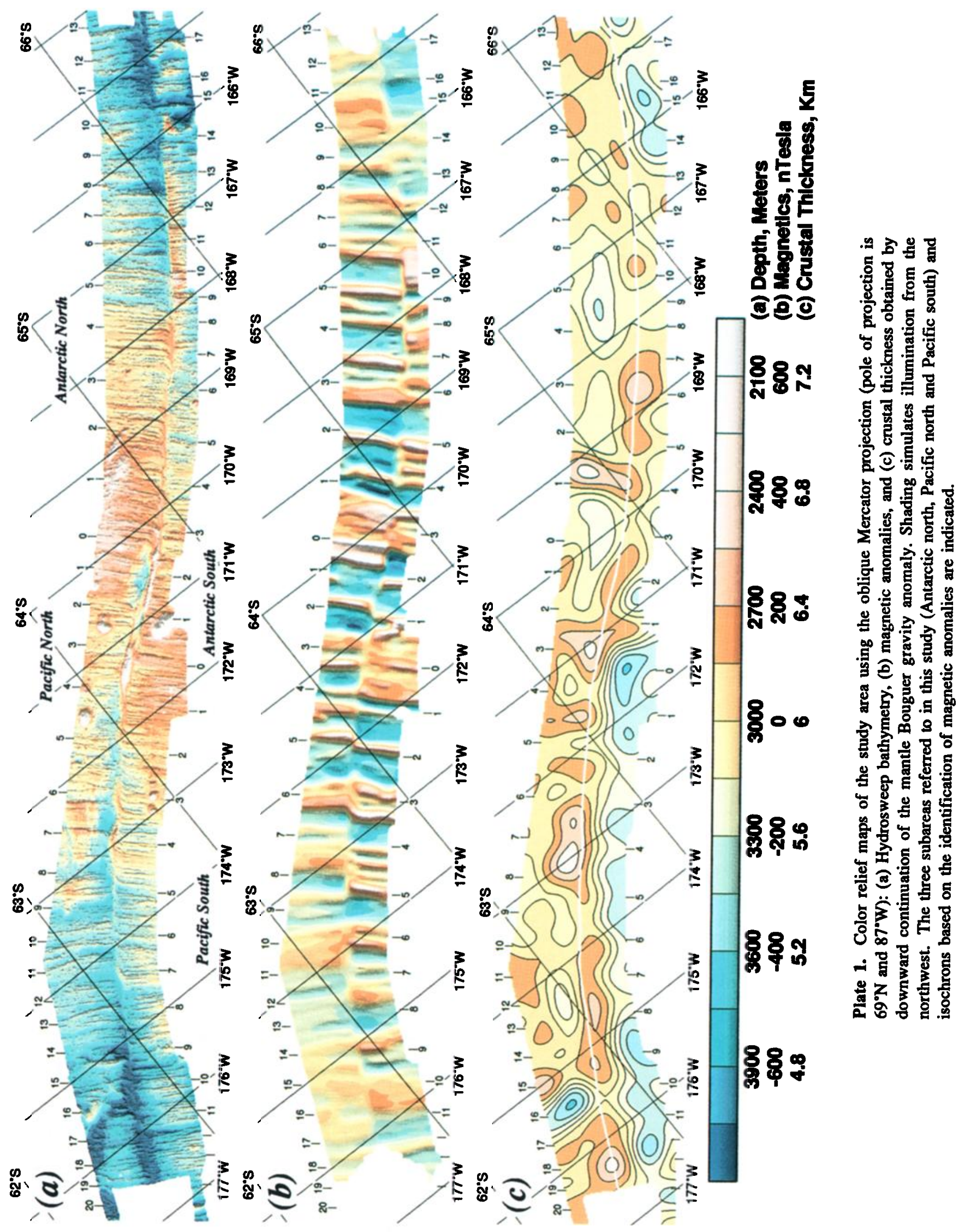



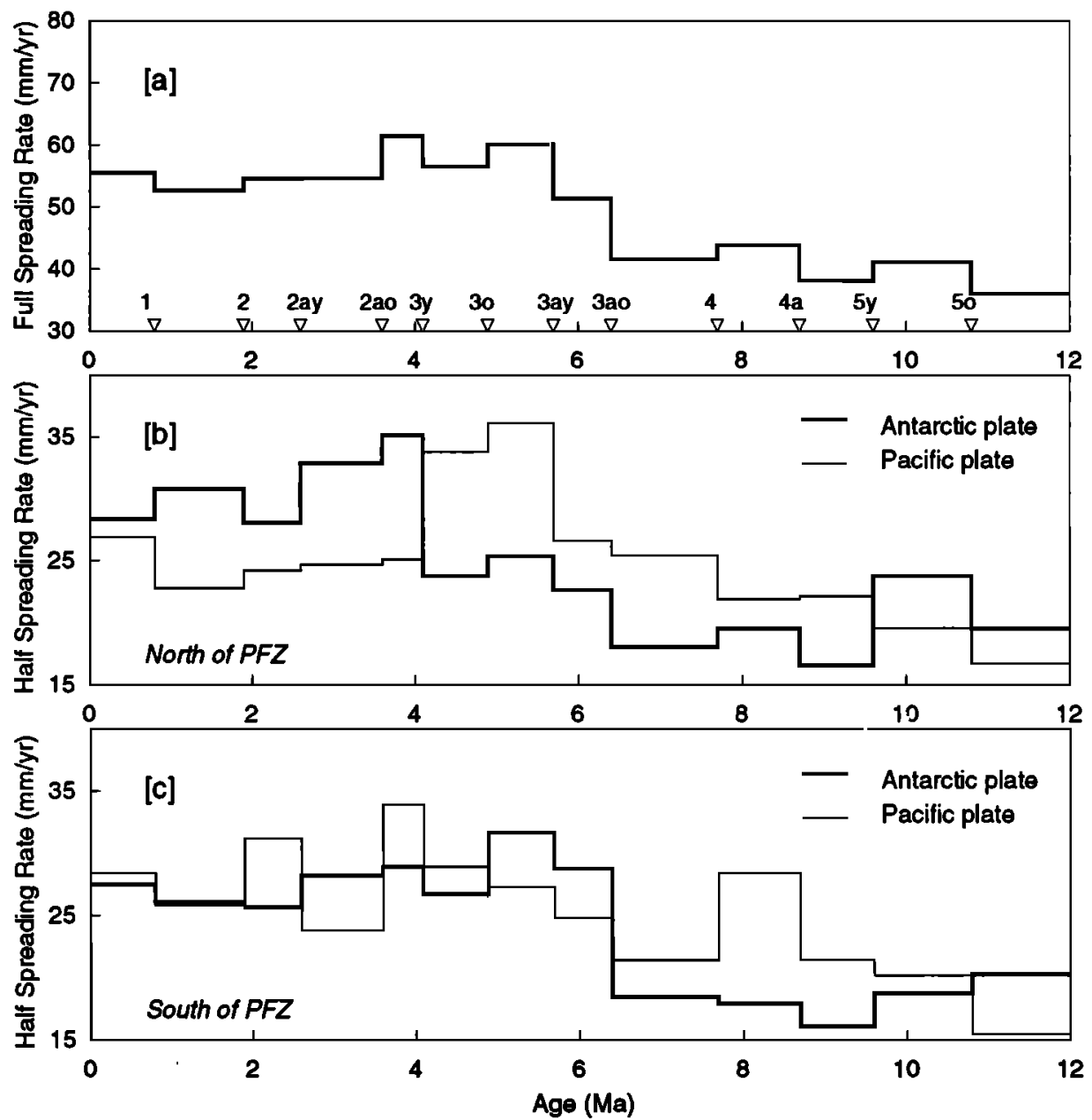

Figure 2. (a) Full spreading rates based on the magnetic anomaly identification [Cande et al., 1992] and the Cande and Kent [1992] geomagnetic polarity timescale. Half spreading rate averages for flow lines north and south of the Pitman Fracture Zone are shown in Figures $2 b$ and $2 c$ respectively.

\section{Abyssal Hill Characterization: Results}

\section{Flow Line Variations}

Estimated values of $H$ and $\lambda$ are displayed as a function of age in Figure 4. With the exception of the terrain identified as locally "anomalous" north of the PFZ (4-6 Ma), there is an overall increase in RMS height with age for all three plotted flow lines. For ages between 0 and $4 \mathrm{Ma}(0-6 \mathrm{Ma}$ for the Pacific south) the well-resolved $H$ estimates are remarkably uniform. Estimates for older crust (8-12 Ma) show larger uncertainties and scatter. The characteristic width estimates show a similar increase with age (Figure 4). However, the differences in $\lambda$ between young and old seafloor on the Pacific north and Pacific south flow lines are not as pronounced.

Table 1 shows the weighted average estimates of the RMS height and characteristic width along with spreading rate and crustal thickness (inferred from the mantle Bouguer gravity anomaly). Abyssal hill size parameters were obtained by grouping individual estimates into $2 \mathrm{Ma}$ age bins, weighted by the inverse of their variance [Goff and Jordan, 1988]. The standard deviation of the parameters are reported in Table 1 along with $1 \sigma$ uncertainties on the weighted average [see Goff, 1991]. While the tabulated uncertainty values represent the resolution of the weighted average, the standard deviation expresses the scatter of a particular parameter. Spreading rate and crustal thickness values shown in Table 1 represent binned averages obtained along the same swaths used to estimate abyssal hill size parameters.

The significance of the change in abyssal hill size parameters between young (0-4 Ma) and old ( $>8 \mathrm{Ma})$ crust can be assessed by examining the weighted averages and their variances. The variance of the difference of two uncorrelated estimates is the sum of the variances of each estimate. Hence the significance of the difference between two weighted averages can be easily established. For the Antarctic north, both $H$ and $\lambda$ estimates obtained for crustal ages less than 4 $\mathrm{Ma}$ are smaller than estimates for crustal ages greater than 8 $\mathrm{Ma}$. The difference is approximately 5 times the square root of the standard deviation of the estimates, so the change in abyssal hill characteristics on that flow line are well resolved at greater than $99.9 \%$ confidence. For the Pacific plate, while the decrease in $H$ is very well resolved (99\% confidence for the Pacific north and $95 \%$ for the Pacific south), the decrease in $\lambda$ is less significant (less than $68 \%$ confidence in both cases). These confidence limits indicate that the bimodal character of $H$ estimates (small values for young crust and large ones for old crust) is very well resolved for both Antarctic and Pacific plate while for $\lambda$ estimates it is only well resolved for the Antarctic plate. 
Pacific Plate

Antarctic Plate

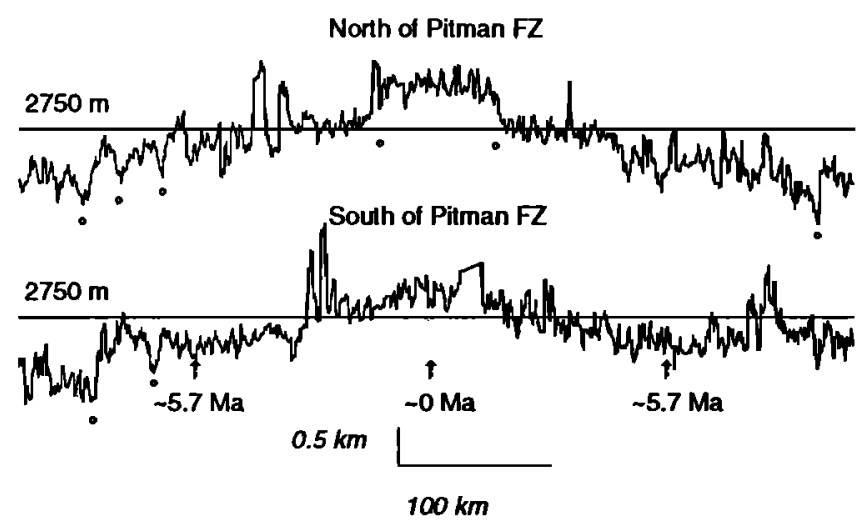

Figure 3. Bathymetric profiles $\sim 600 \mathrm{~km}$ long extending to both sides of the ridge crest north and south of the PFZ. The solid line indicates the $2750 \mathrm{~m}$ depth. The axial high south of the Pitman Fracture Zone is $-300 \mathrm{~m}$ deeper than the axis north of the PFZ. The open circles indicate the large relief scarps that were avoided due to unstable inversion results. Seamounts were also excluded from the analyses (sharp peaks); the large near-axis seamount south of the PFZ on the Antarctic plate was removed for display purposes.

Other important observations of abyssal hill variability derived from Table 1 include the following: (1) for crustal ages between 0 and $4 \mathrm{Ma}$ north of the PFZ, we observe a remarkable symmetry in abyssal hill size parameters for opposite ridge flanks. In contrast, a well-resolved difference for both $H$ and $\lambda$ estimates between the Pacific north and Antarctic north flow lines is observed for isochrons in the 8-12 Ma range. Abyssal hills along the Antarctic north flow line are on average $47 \mathrm{~m}$ taller and $2 \mathrm{~km}$ wider than those along the Pacific north flow line in the same age range; (2) RMS height and characteristic width estimates for crustal ages between 4 and $6 \mathrm{Ma}$ are significantly higher for the flow lines north of the PFZ. This corresponds to the age range of the locally "anomalous" terrain previously defined; and (3) when contrasting Pacific north and south, we find that for crustal ages between 0 and 4 $\mathrm{Ma}$, both $H$ and $\lambda$ estimates are larger (at $95 \%$ confidence) to the south of the PFZ. At older ages ( $>6 \mathrm{Ma}$ ), the increase on average abyssal hill size to the south of the PFZ is only statistically significant for $\lambda$ estimates.

Table 1 also illustrates the differences in the averaged weighted estimates between swaths taken adjacent $(\sim 5 \mathrm{~km})$ and away $(\sim 17-40 \mathrm{~km})$ from the PFZ. For all subareas, we find significantly larger estimates of $H$ (by $25-58 \mathrm{~m}$ ) near the PFZ relative to the estimates obtained for the swaths taken away from the PFZ. Although no significant changes in characteristic width estimates are observed to the north of PFZ, $\lambda$ is smaller near the PFZ for the Pacific south (by 2.2$2.4 \mathrm{~km}$ ).

\section{Relationship With Spreading Rate}

The negative relation between the binned abyssal hill size parameters and the spreading rate history is illustrated in Figure 5. The negative Pearson's correlation coefficient $R$ and estimated confidence $C$ [Press et al., 1991], between $H$ estimates and full spreading rates are high for all subareas when the locally "anomalous" seafloor fabric is excluded from the regression analysis $(R=-0.93,-0.96$, and -0.99 and $C=96$, 97, and 99\% for Antarctic north, Pacific north, and Pacific south, respectively; Figure 5a). The degree of correlation between $\lambda$ estimates and full spreading rate is also high $(R=-$ $0.85,-0.83$, and -0.85 and $C=94,94$, and $96 \%$ for Antarctic north, Pacific north, and Pacific south, respectively; Figure 5b). The anomalous character of the seafloor fabric for 4-6 Ma old crustal ages is clearly documented here as a deviation from the negative trend between abyssal hill size parameters and spreading rates (correlation coefficients are smaller when the locally "anomalous" fabric is included). The negative correlation between abyssal hill size parameters and full spreading rate averaged for the three subareas is shown in Figures $5 \mathrm{c}$ and $5 \mathrm{~d}$ as regional averages. When the locally "anomalous" estimates are excluded, the correlation coefficients and confidence limits between spreading rates and abyssal hill size parameters are $R=-0.99, C=97 \%$ for $H$ estimates and $R=-0.93$ and $C=96 \%$ for $\lambda$ estimates. We have also plotted in Figures $5 \mathrm{c}$ and $5 \mathrm{~d}$ the weighted estimates obtained for swaths adjacent to the PFZ (averaged for the three subareas). The RMS height averages in this case clearly plot above the local trend.

Figure 6a demonstrates a well-resolved high positive correlation between RMS height and characteristic width $(R=0.97,0.95$, and 0.89 and $C=98,98$, and $97 \%$ for Antarctic north, Pacific north, and Pacific south, respectively). The correlation coefficient between RMS height and characteristic width estimates averaged for the three subareas is high at high confidence levels ( $R=0.92$ and $C=98 \%$; Figure $6 \mathrm{~b}$ ). The weighted estimates obtained for swaths adjacent to the PFZ once again show a clear departure from the regional trend.

\section{Relationship With Crustal Thickness}

Abyssal hill size parameters and crustal thickness are not systematically correlated as illustrated in Figure 7. The degree of correlation between $\lambda$ and crustal thickness is small for all subareas at low confidence levels $(R=0.23,-0.32$, and -0.30 and $C=42,56$, and $54 \%$ for Antarctic north, Pacific north, and Pacific south, respectively). The same holds for the correlation between $H$ and crustal thickness $(R=0.14,-0.33$, and -0.60 and $C=26,57$, and $85 \%$ for Antarctic north, Pacific north, and Pacific south, respectively). Furthermore, the crustal thickness of the identified "anomalous" seafloor fabric (4-6 Ma) is not notably different from surrounding terrain (Table 1). Adjacent to the PFZ, variations in crustal thickness are also small and not systematically correlated with abyssal hill size parameters (Table 1).

Flow line variations in crustal thickness are small (maximum of $\sim 0.4$ and $\sim 0.2$ for the Antarctic and Pacific plate, respectively; Table 1). The most significant variations in crustal thickness are seen across the PFZ by contrasting Pacific north and south (Table 1). For a fixed crustal age, the average amount of crustal thinning from north to south ranges from 0.5 to $0.7 \mathrm{~km}$, with Pacific north crust uniformly thicker than Pacific south crust. In this case, abyssal hill size parameters do appear to be well-correlated with crustal thickness. With the single exception of the anomalous terrain (4-6 Ma), average $H$ and $\lambda$ estimates are uniformly smaller (though the difference is not always statistically significant) on the Pacific north flow line than those on the Pacific south flow line at similar crustal ages (Table 1). More quantitatively: for crustal ages $<4 \mathrm{Ma}$, we find that the decrease in crustal thickness by $0.5-0.7 \mathrm{~km}$ from north to south is 

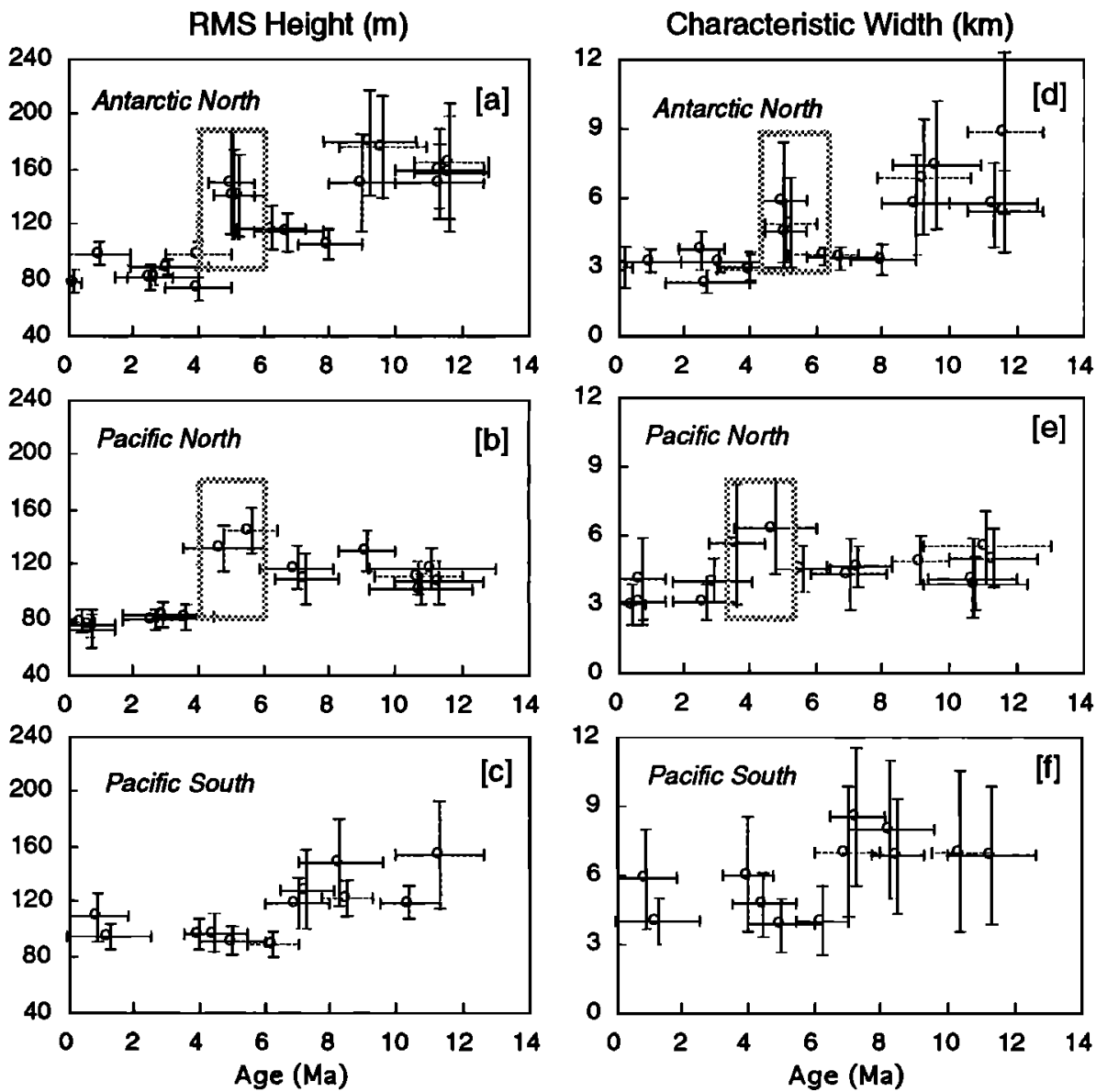

Figure 4. Estimated flow line variations in abyssal hill RMS height $H$ and characteristic width $\lambda$ for the three subareas. The estimates, obtained for individual swaths, are shown as open circles with error bars denoting one standard deviation. The location of the locally "anomalous" seafloor fabric (4-6 Ma crustal age) is indicated with stippled boxes.

accompanied by a statistically significant increase in both $H$ and $\lambda$ estimates (by $24 \%$ and $41 \%$ respectively over $95 \%$ confidence level). For ages $>6 \mathrm{Ma}$, the $0.5-0.7 \mathrm{~km}$ crustal thinning across the PFZ coincides with an increase in only $\lambda$ estimates (by $65 \%$ at $99 \%$ confidence; the small increase in $H$ is not well resolved).

\section{Discussion and Interpretation}

The main assumption in this study is that off-axis abyssal hills are an indirect record of the axial processes (faulting and volcanism) which created them and thus provide an excellent opportunity to quantify temporal variations in the dynamics of mid-ocean ridge processes. Flow line variations in $H$ and $\lambda$ estimates observed in this study (Figure 5) demonstrate that abyssal hills formed during slower spreading periods are significantly larger than hills created during the faster spreading interval.

In this discussion, we first analyze the overall spreading rate dependence on abyssal hill morphology. Deviations from this simple model are explored in terms of crustal thickness variations (as inferred from mantle Bouguer gravity anomalies) and along-axis variations in extensional deformation and volcanism. We then discuss our results in the framework of inside/outside corner asymmetries and present the findings of a large-scale topographic roughness analysis (over $40 \mathrm{Ma}$ ).

\section{Spreading Rate Dependence}

The primary result of this study is that abyssal hill size characteristics are negatively correlated with spreading rate (Figure 5), in agreement with the results of previous studies [Menard, 1967; Goff, 1991; Malinverno, 1991; Hayes and Kane, 1991; Goff, 1992]. We find that during slower spreading periods (ages $>8 \mathrm{Ma}$; full rates $36-44 \mathrm{~mm} / \mathrm{yr}$ ), abyssal hill estimates are $31-86 \%$ taller and $21->100 \%$ wider than during the faster spreading intervals (ages $<4 \mathrm{Ma}$; full rates $52-63 \mathrm{~mm} / \mathrm{yr}$ ). The locally "anomalous" character of the seafloor fabric for 4-6 Ma old crust is a notable exception to the spreading rate dependence.

The relationship between abyssal hill morphology and spreading rate based on this study, and on abyssal hill size parameters given by Goff [1991], is illustrated in Figure 8. An increase in both RMS height and characteristic width as spreading rate decreases is observed. However, the very fast spreading rate data (Pacific-Nazca, PN) display slightly larger abyssal hill size parameters than the fast spreading rate data (Pacific-Cocos, PC). There is a good agreement between the abyssal hill size parameters proposed by this study for 0-2 Ma (full rates $\sim 55 \mathrm{~mm} / \mathrm{yr}$ ), and the parameters found for the Pacific-Rivera and African-Indian subsets (PR+AI). For abyssal hills created during slower spreading periods (10-12 Ma, full rates $\sim 39 \mathrm{~mm} / \mathrm{yr}$ ), $H$ and $\lambda$ estimates are between the values found for the Mid-Atlantic Ridge (MAR) and PR+AI. 
Table 1. Weighted Average Estimates

\begin{tabular}{|c|c|c|c|c|c|c|}
\hline Age, Ma & $\begin{array}{l}\text { Full Spreading } \\
\text { Rate, mm/yr }\end{array}$ & $\begin{array}{c}\text { Crustal } \\
\text { Thickness, km }\end{array}$ & $H, \mathrm{~m}$ & $\sigma, \mathrm{m}$ & $\lambda, \mathrm{km}$ & $\sigma, \mathrm{km}$ \\
\hline \multicolumn{7}{|c|}{ Antarctic North } \\
\hline $0-2$ & 55 & 6.1 & $91 \pm 10$ & 10.0 & $3.1 \pm 0.5$ & 0.1 \\
\hline $2-4$ & 57 & 5.9 & $85 \pm 4$ & 8.1 & $3.1 \pm 1.2$ & 0.5 \\
\hline $4-6$ & 59 & 5.8 & $144 \pm 19$ & 4.5 & $4.9 \pm 1.1$ & 0.5 \\
\hline $6-8$ & 44 & 6.0 & $113 \pm 8$ & 5.1 & $3.4 \pm 0.4$ & 0.1 \\
\hline $8-10$ & 40 & 6.0 & $170 \pm 21$ & 13.0 & $6.7 \pm 1.5$ & 0.7 \\
\hline $10-12$ & \multicolumn{5}{|c|}{ Pacific North } & 1.4 \\
\hline $0-2$ & 55 & 6.2 & $77 \pm 6$ & 3.0 & $3.3 \pm 0.8$ & 0.5 \\
\hline $2-4$ & 57 & 6.2 & $82 \pm 5$ & 2.1 & $4.0 \pm 0.9$ & 1.0 \\
\hline $4-6$ & 59 & 6.2 & $139 \pm 12$ & 6.5 & $5.2 \pm 1.1$ & 0.9 \\
\hline $6-8$ & 44 & 6.0 & $115 \pm 12$ & 4.0 & $4.5 \pm 0.9$ & 0.2 \\
\hline $8-10$ & 40 & 6.1 & $130 \pm 14$ & 14.0 & $4.9 \pm 1.1$ & $\begin{array}{l}0.2 \\
1.1\end{array}$ \\
\hline \multicolumn{7}{|c|}{$\begin{array}{c}109 \pm 7 \\
\text { Pacific South }\end{array}$} \\
\hline $0-2$ & 55 & 5.5 & $100 \pm 7$ & 7.0 & $4.7 \pm 1.2$ & 0.9 \\
\hline $2-4$ & 57 & 5.6 & $97 \pm 11$ & 11.0 & $6.0 \pm 2.5$ & 2.5 \\
\hline $4-6$ & 59 & 5.5 & $90 \pm 7$ & 5.4 & $4.2 \pm 0.8$ & 0.4 \\
\hline $6-8$ & 44 & 5.5 & $123 \pm 17$ & 5.0 & $7.8 \pm 2.1$ & 0.8 \\
\hline $8-10$ & 40 & 5.4 & $131 \pm 17$ & 13.5 & $7.4 \pm 2.0$ & 0.6 \\
\hline $10-12$ & 39 & 5.5 & $129 \pm 20$ & 17.5 & $6.9 \pm 2.3$ & 0.1 \\
\hline \multicolumn{7}{|c|}{ Adjacent to PFZ: Antarctic North } \\
\hline $0-2$ & 55 & 6.1 & $116 \pm 6$ & 4.8 & $4 \pm 0.4$ & 0.3 \\
\hline $2-4$ & 57 & 6.1 & $143 \pm 11$ & 11.0 & $3 \pm 0.5$ & 0.5 \\
\hline \multicolumn{7}{|c|}{ Adjacent to PFZ: Pacific North } \\
\hline $0-2$ & 55 & 6.1 & $119 \pm 8$ & 8.0 & $3.4 \pm 0.4$ & 0.3 \\
\hline $2-4$ & 57 & 6.4 & $126 \pm 15$ & 15.0 & $4.1 \pm 0.5$ & 0.5 \\
\hline \multicolumn{7}{|c|}{ Adjacent to PFZ: Pacific South } \\
\hline $0-2$ & 55 & 5.9 & $126 \pm 9$ & 7.0 & $2.5 \pm 0.8$ & 0.8 \\
\hline $2-4$ & 57 & 5.9 & $124 \pm 9$ & 6.0 & $3.6 \pm 0.8$ & 1.0 \\
\hline
\end{tabular}

One likely mechanism for the negative correlation between abyssal hill size and spreading rate is the variation in axial thermal structure associated with spreading rate: a cooler lithosphere at slow spreading ridges has a thicker elastic core and thus is able to support larger abyssal hills [i.e., Goff, 1991]. In contrast, only small abyssal hills can be supported by the thinner elastic layer resulting from higher ridge crest temperatures in the vicinity of fast spreading ridges.

Another possible mechanism for explaining the negative trend between abyssal hill size and spreading rate is the likely change in the axial morphology that might have accompanied a change in spreading rate. Mid-ocean ridges spreading at full rates $<35 \mathrm{~mm} / \mathrm{yr}$ are generally characterized by the presence of a rift valley $1-2 \mathrm{~km}$ deep and $15-20 \mathrm{~km}$ wide, while fast spreading ridges ( $>60 \mathrm{~mm} / \mathrm{yr}$ full rates) are likely to be associated with an axial high $100-200 \mathrm{~m}$ high and $1-2 \mathrm{~km}$ wide [e.g., Macdonald, 1982]. Malinverno [1993] proposed that for a fixed axial depth, spreading rate variations as small as 15 $\mathrm{mm} / \mathrm{yr}$ are enough to trigger a change from a rift valley to an axial high. Given the spreading rate variability documented for the study area between the older and younger portions of the seafloor (36-63 mm/yr full rate), it is reasonable to expect that the axial topography has varied accordingly over the past 12 m.y. Rift valleys, which probably characterized the ridge axis when the older seafloor was created, are accompanied by very large inward facing faults which, after back tilting over the rift mountains, are preserved as abyssal hill structures [e.g., Macdonald, 1982]. Mid-ocean ridges with axial highs do not undergo this form of intensive tectonism. Thus it is likely that some component of the negative relationship between abyssal hill size properties and spreading rate is related to the transition from axial valley to axial high morphology.

The theoretical formulation for topographic roughness due to normal faulting of Malinverno and Cowie [1993] proposes that the characteristic width of a faulted block is controlled by the flexural wavelength. Their formulation assumes the lithosphere behaves like an elastic plate, faults have a vertical dip and infinite length, faults do not interact, and fault parameters and locations represent independent variables. According to the theory of Malinverno and Cowie [1993], the flow line variations in $\lambda$ estimates seen in Figure 4 can be explained in terms of temporal changes in the strength of the lithosphere in the vicinity of the ridge crest and, by implication, axial thermal structure. If abyssal hills are formed by normal faulting, then these predictions are in good agreement with inferred variations in flexural rigidity based on the spreading rate history: wider fault blocks are formed during slower spreading periods when the lithosphere is elastically stronger. 

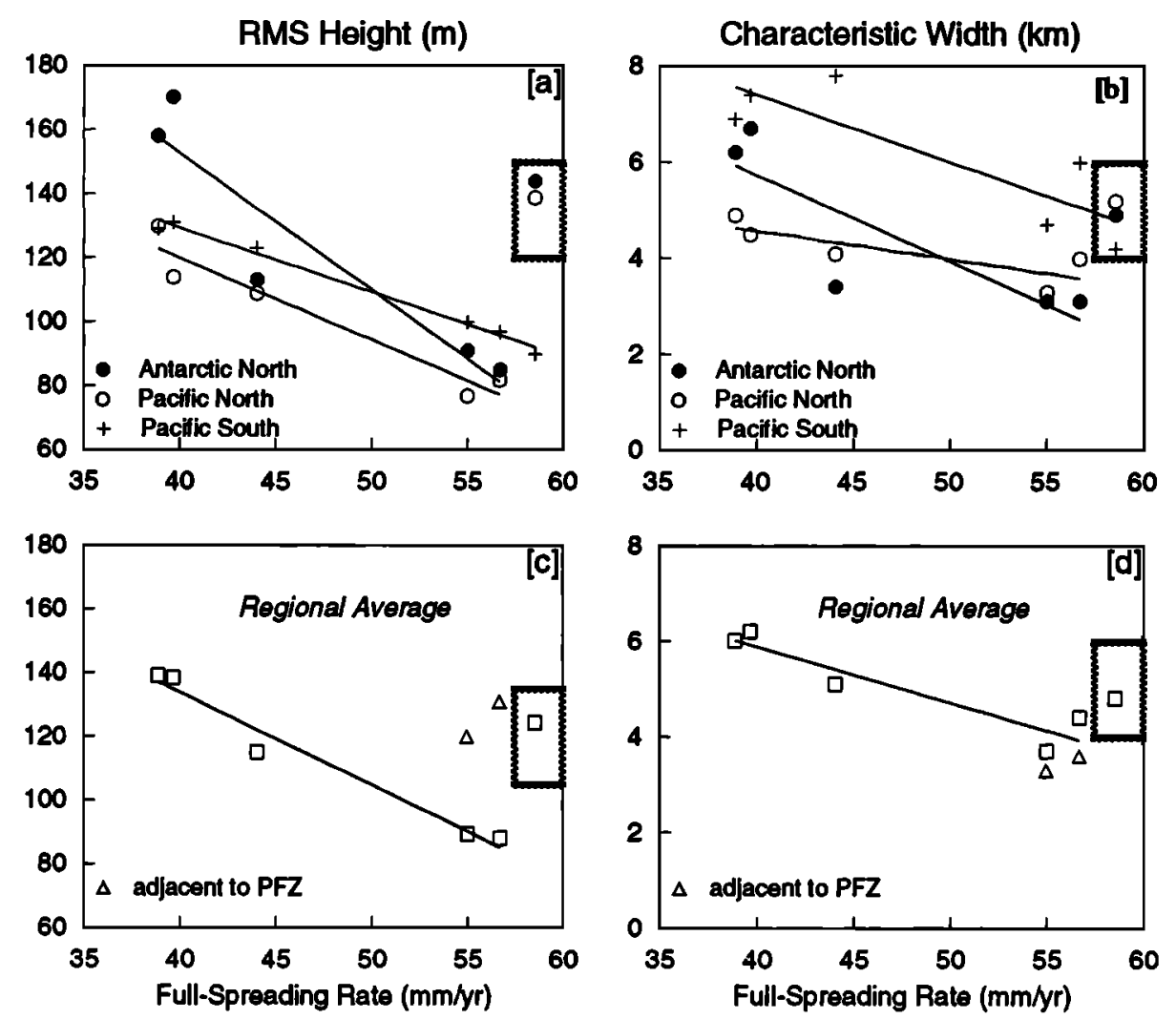

Figure 5. Weighted averages (binned at $2 \mathrm{Ma}$ ) of (a) RMS height and (b) characteristic width as a function of full spreading rates for the three subareas and associated linear regressions. The estimates corresponding to the locally "anomalous" seafloor fabric (4-6 Ma) are indicated with stippled boxes. (c) Weighted $H$ and (d) $\lambda$ estimates averaged for the three subareas (regional averages) are shown as opened squares. The averaged estimates obtained for swaths adjacent to the PFZ ( $\sim 5 \mathrm{~km}$ from its topographic trace) are shown as open triangles. In all cases the locally "anomalous" seafloor fabric was left out from the regression analysis shown as a straight line.

The normal faulting theory of Malinverno and Cowie [1993] predicts that $H$ is proportional to $\sqrt{\varphi<h^{2}>\alpha}$, where $\varphi<h^{2}>$, the amount of extension is defined as the product of fault density $\varphi$ times mean squared fault scarp height $\left\langle h^{2}\right\rangle$ and $\alpha$ is the flexural wavelength. Based on the gross similarity between the power spectra of Malinverno and Cowie [1993] and Goff and Jordan [1988], the flexural wavelength and characteristic width used in this study are intuitively related. Therefore, for fault-generated topography we anticipate a positive correlation between $H$ and $\lambda$, consistent with our observations (Figure 6). However, it is important to point out that a similar positive trend between $H$ and $\lambda$ is also expected to develop as a result of constructional volcanism. Taller volcanic edifices are predicted to be wider based on maximum slope of repose arguments [e.g., Smith and Jordan, 1988]. In this context, a possible explanation for the flow line changes in abyssal hill size parameters is that during the slower spreading period, the cooler and stronger lithosphere will be able to support larger constructional edifices relative to faster spreading periods.

Previous work has demonstrated that abyssal hills generated at the slow spreading Mid-Atlantic Ridge tend to have a positive correlation between $H$ and $\lambda$ [Goff, 1991, 1992; Goff et al., 1992], whereas those generated along the fast spreading East Pacific Rise tend toward a negative [Goff, 1991] or flat [Goff et al., 1993] correlation. In this respect, the positive correlation between flow line variations in $H$ and $\lambda$ observed here (Figure 6) suggests that the intermediate spreading Pacific-Antarctic Ridge bears more resemblance to slow spreading ridges than fast spreading ridges in the way abyssal hills are formed. However, the negative/flat correlation between $H$ and $\lambda$ derived from the East Pacific Rise abyssal hills probably reflects along-axis variations associated with segmentation, whereas the positive correlation for MidAtlantic Ridge abyssal hills holds for both flow line and segmentation associated variability. Although our along-axis sampling is slim, the evidence from Table 1 suggests that while there is an increase in $H$ approaching the PFZ, there is no corresponding increase in $\lambda$. This behavior is more akin to abyssal hills generated at fast spreading rates. Along-axis variability will be discussed in a later section.

\section{Crustal Thickness Dependence}

The negative relation between abyssal hill size and crustal thickness inferred from mantle Bouguer gravity anomalies at slow spreading ridges has been used to suggest that abyssal hills are controlled by the axial temperature structure and/or deep melt supply [Goff et al., 1992; Lin et al., 1992]. Abyssal hills underlain by thinner crust are likely to be associated with a stronger lithosphere (due to greater proportion of mantle rocks) and cooler axial temperature 


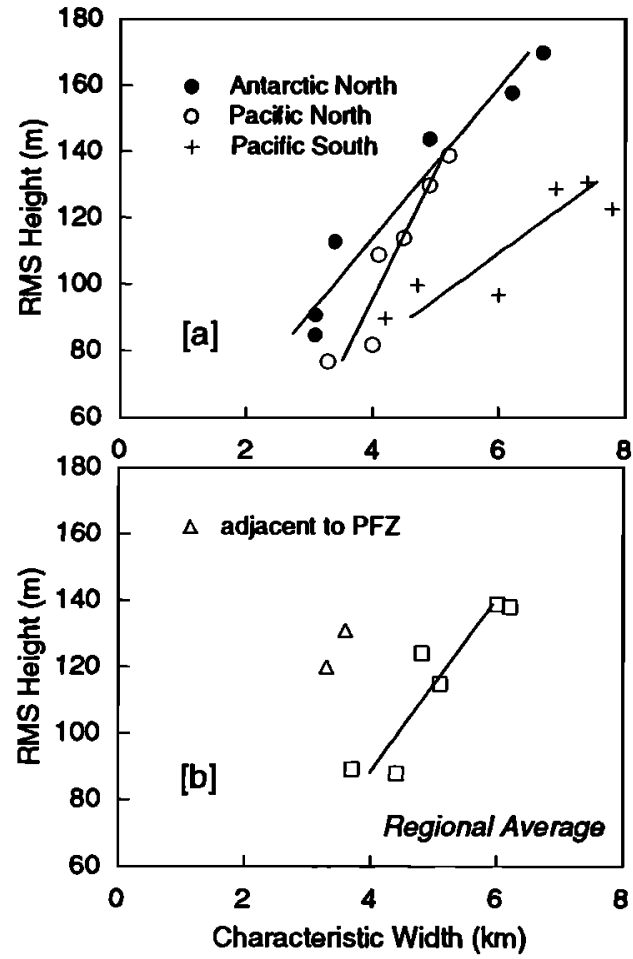

Figure 6. (a) Weighted averages (binned at $2 \mathrm{Ma}$ ) of RMS height against characteristic width for the three subareas and associated linear regressions. (b) The weighted estimates averaged for the three subareas (regional values) are shown as opened squares. The averaged estimates obtained for swaths adjacent to the PFZ (triangles) and clearly depart from the regional averages (squares). In all cases the locally "anomalous" seafloor fabric was included in the regression analysis shown as a straight line.

regime (due to smaller magma supply). Both factors favor the formation of larger abyssal hills.

For the study area, flow line variations in crustal thickness are small in magnitude (maximum of 0.4 and $0.2 \mathrm{~km}$ for Antarctic and Pacific plate, respectively; Table 1) when compared to the $\sim 2 \mathrm{~km}$ variations reported by Lin et al. [1992] for the Mid-Atlantic Ridge. The correlation between abyssal hill size parameters and crustal thickness is generally small and insignificant along flow lines for all subareas (Figure 7). Also, neither the anomalous zones nor the asymmetry in abyssal hill size estimates found for crustal ages $>8 \mathrm{Ma}$ to the north of the PFZ can be associated with differences in crustal thickness. The most significant variations in crustal thickness (0.5-0.7 km) are seen by comparing Pacific north and south subareas. In this case, crustal thickness variations across the PFZ are well-correlated with average abyssal hill size parameters; that is, thinner crust south of PFZ is associated with larger $H$ and $\lambda$ (Table 1). These observations may most simply be explained by a threshold sensitivity of abyssal hill morphology to crustal thickness variations: where crustal thickness variations are too small (along flow lines), their influence on abyssal hill morphology cannot be detected or differentiated from other influences on abyssal hill formation; where we do see significant variations in crustal thickness (across the PFZ), we observe differences in abyssal hill characteristics which may be attributable to these variations.
The locally "anomalous" character of 4-6 Ma abyssal hill fabric north of the PFZ represent a clear exception to the spreading rate dependence. Contrary to our expectations, these larger abyssal hills are not associated with crustal thinning. An analysis of the gravity field surrounding the surveyed area suggests the presence of propagating rift and a relict fracture zone located to the north of the PFZ (Figure 1). These, together with the fracture zone subparallel lineaments found only on the Pacific plate north of the PFZ (6-8 Ma) and the clockwise rotation in abyssal hill lineaments of $\sim 10^{\circ}$ for both ridge flanks $(\sim 6 \mathrm{Ma})$, may be indicative of recent changes in the stress field. We speculate that spatial and temporal asymmetries in the regional stress field may partially account for some of the morphological differences found in this study.

\section{Along-Axis Variations}

We find that adjacent to the PFZ (toward the segment ends), $H$ estimates are systematically larger, while $\lambda$ estimates either do not significantly change (flat correlation between $H$ and $\lambda$ north of the PFZ) or are up to $40 \%$ smaller (negative correlation between $H$ and $\lambda$ south of the PFZ) (Table 1). Goff [1991] demonstrates that $H$ increases, while $\lambda$ decreases approaching axial discontinuities for the northern East Pacific Rise. Along the southern East Pacific Rise [Goff et al., 1993], $\boldsymbol{H}$ also increases approaching discontinuities, while $\lambda$ remains relatively constant. For both cases, the greater amount of extension associated with the increase in RMS height estimates toward ridge segment ends is interpreted as
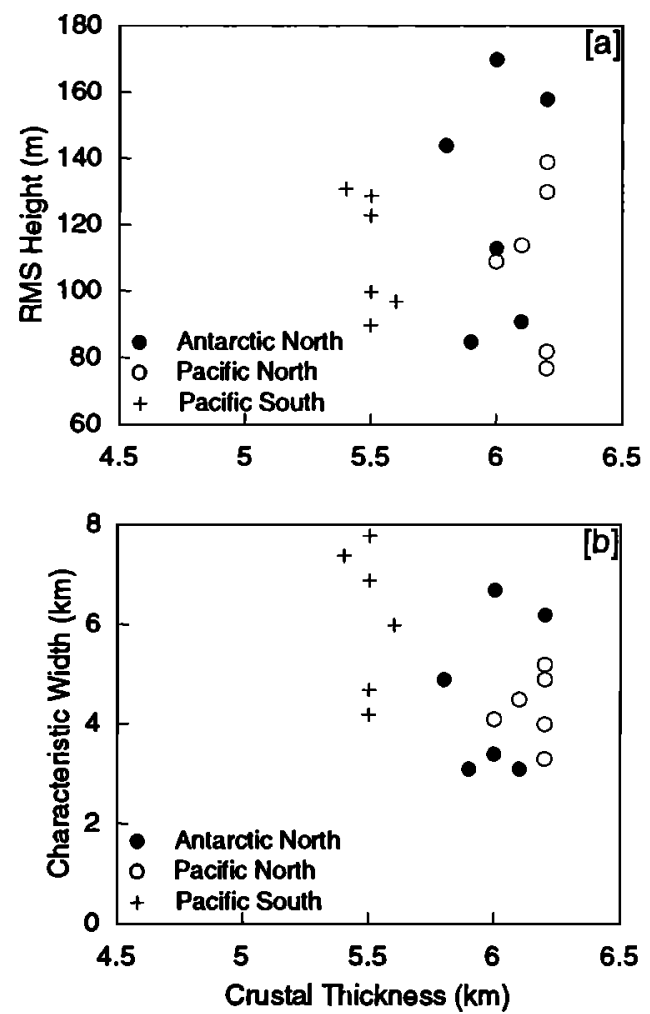

Figure 7. Weighted averages (binned at $2 \mathrm{Ma}$ ) of (a) RMS height and (b) characteristic width as a function of crustal thickness (inferred from mantle Bouguer gravity anomaly). No systematic trend is observed between abyssal hill size parameters and crustal thickness for the three subareas. Crustal thickness estimates are more uniform and consistently smaller south of the PFZ. 

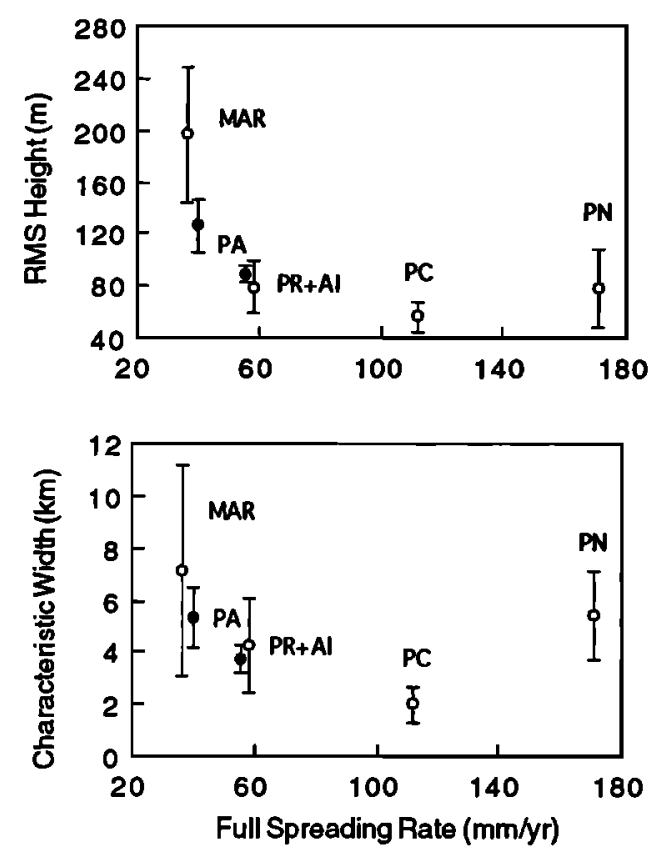

Figure 8. Averages of abyssal hill size parameters (a) RMS height and (b) characteristic width as a function of full spreading rates. Estimates plotted for the Pacific-Antarctic Ridge are shown as solid circles and represent averages for the 0-2 $\mathrm{Ma}$ (full rate $\sim 55 \mathrm{~mm} / \mathrm{yr}$ ) and for 10-12 $\mathrm{Ma}$ (full rates $\sim 39$ $\mathrm{mm} / \mathrm{yr}$ ) time intervals. The open circles indicate the near-axis abyssal hill size estimates reported by Goff [1991]. PR+AI, PC, PN, and MAR refer to the Pacific-Rivera and Africa-India, Pacific-Cocos, Pacific-Nazca, and Mid-Atlantic Ridge, respectively.

indicative of a cooler temperature structure and/or smaller magma supply [Goff, 1991; Goff et al., 1993].

In the context of the normal faulting theory of Malinverno and Cowie [1993], the observation that toward the segment ends $H$ increases while $\lambda$ remains the same (to the north of the PFZ) can be interpreted as an increase in the amount of extension without a corresponding significant increase in the flexural rigidity (which is the main control on $\lambda$ ). This contrasts with Goff et al. [1993] thermal arguments which, in the context of Malinverno and Cowie [1993] theory, predicts higher characteristic width estimates toward segment ends. The cooler temperature structure near segment ends would be associated with a stronger lithosphere and therefore larger $\lambda$. If faulting is the main control on abyssal hill morphology, then according to the theory of Malinverno and Cowie [1993], the lack of significant variations in $\lambda$ estimates toward the segment ends observed in the study area to the north of the PFZ argues against significant along-axis variations in flexural rigidity.

The behavior of volcanic extrusives provides an additional consideration in the along-axis variation in abyssal hill morphology. It is possible that more robust and steady state magma supply toward the segment midpoint will cause volcanic flooding of topographic lows. This smoothing effect related to volcanism will decrease $H$ estimates and possibly result in the larger $\lambda$ estimates we observe away from the fracture zone in the south flow lines. The differences in the correlation between $H$ and $\lambda$ (flat north of the PFZ and negative south of the PFZ) may therefore reflect variations from segment to segment in the contribution of volcanism to abyssal hill morphology.

The difference in flow line (positive) and along-axis (flat/negative) correlations between $H$ and seen in the PFZ survey area suggest that abyssal hill variations associated with ridge segmentation occur by different mechanisms than those associated with temporal variability in mid-ocean ridge dynamics. We speculate, based on the above discussion, that variations in abyssal hill parameters associated with ridge segmentation are caused by the interplay between extensional tectonism and volcanism (correlation between $H$ and $\lambda$ will depend on the relative importance of each mechanism). In contrast, temporal changes in abyssal hill parameters are due to variations in predominantly just one of these processes (resulting in a positive correlation between $H$ and $\lambda$ estimates).

\section{Inside/Outside Corner Asymmetries}

Inside/outside comers asymmetries may develop as a result of mechanical deformation associated with normal faulting. Based on multichannel seismic reflection profiling and deep drilling results for oceanic crust, Mutter and Karson [1992] proposed a structural model for slow spreading ridges in which low angle normal faults (footwall detachment surfaces) dip obliquely to the spreading direction towards the ridgetransform intersection. According to this model, the inside corner "detachment surface" is broken up by high-angle normal faults. Thinner crust (stronger lithosphere) and larger abyssal hills are predicted for the inside comer due to greater amounts of extension relative to the outside comer.

The morphological and structural predictions based on the "detachment surface" model have been recently supported by sidescan, bathymetry and gravity data on the Mid-Atlantic Ridge [Tucholke et al., 1992; Goff et al., 1992]. Our observations for the Pacific north (inside comer) and Antarctic north (outside corner), however, do not support the "detachment surface" model predictions. Over crustal ages $>8$ Ma (full rates $36-44 \mathrm{~mm} / \mathrm{yr}$ ), no systematic inside/outside corner asymmetries in crustal structure are observed (Plate 1c). In the faster spreading portion (ages <4 Ma; full rates 52-63 $\mathrm{mm} / \mathrm{yr}$ ) some asymmetry in crustal thickness is observed to the north of the PFZ, but it is variable and can be related to volcanic overprinting. At crustal ages $>8 \mathrm{Ma}$, there is a large inside/outside comer asymmetry in estimates of $H$ and $\lambda$ north of the PFZ but it is in the opposite sense to the predictions; that is, abyssal hills found on the outside corner are significantly larger than those on the inside comer (Figure 4 and Table 1). At younger ages there is no significant asymmetry in abyssal hill characteristics. In this respect, the studied portion of the Pacific-Antarctic Ridge has a morphological/structural behavior more similar to a fast spreading ridge (no systematic inside/outside corner asymmetries) than a slow spreading ridge.

\section{Topographic Roughness}

Malinverno [1990] developed a roughness-length method which consists of segmenting a profile in windows of varying lengths and calculating the average roughness for any given window length. Like the power spectral density, the roughness-length relationship follows a power law distribution for wavelengths less than a factor proportional to the characteristic flexural length scale $\alpha$. Using independent estimates for fault scarp height, fault spacing, and flexural 
wavelength, Malinverno and Cowie [1993] found that normal faulting can account for all the observed topographic roughness of the East Pacific Rise $\left(15^{\circ} \mathrm{N}-14^{\circ} \mathrm{S}\right)$. Although such independent estimates are not available for the study area, the "roll-off" point (break in the power law behavior) in a roughness versus window length graph can be used to make inferences on the average flexural strength of the lithosphere. Specifically, it follows from the formulation of Malinverno and Cowie [1993] that for window lengths greater than $2.8 \alpha$. the average predicted roughness is a constant independent of the window length. Altematively, for window lengths less than $2.8 \alpha$, the average predicted roughness is proportional to the square root of the window length (power law holds in this case).

In order to evaluate whether the statistically significant increase in the averaged $\lambda$ estimate south of the PFZ detected for the past $12 \mathrm{~m} . y$. is associated with long-term differences in the flexural strength of the lithosphere, we analyzed the topographic roughness on either side of the Pacific-Antarctic Ridge up to $40 \mathrm{Ma}$. In Figure $9 \mathrm{a}$, the circles represent the observed topographic roughness (obtained using the roughness-length method) for two flow lines $\sim 1350 \mathrm{~km}$ long to the north and south of the PFZ. For the segment south of the PFZ, the "roll-off" from the power law regime to a flat line happens at larger window lengths than for the segment south of the PFZ. The formulation of Malinverno and Cowie [1993] predicts that the characteristic flexural wavelength scale for the southern ridge segment $(\alpha . \sim 22 \mathrm{~km} ; T,-5.6 \mathrm{~km})$ is larger than the northern one $\left(\alpha . \sim 11 \mathrm{~km} ; T_{,} \sim 2.1 \mathrm{~km}\right)$, and therefore the lithosphere created at the southern ridge segment is on average stronger than the northern segment. This inferred change in flexural strength is consistent with the current axial morphology (a rift valley to the south of the PFZ and an axial high to its north) and the crustal thinning we observe from north to south across the PFZ (Plate 1c and Table 1). Figure 9b illustrates the power spectral density for the same flow lines used in topographic roughness analysis. We note that for almost all wave numbers the southern segment has more topographic power than the northern one (except in the 0.2 $0.5 \mathrm{~km}^{-1}$ range).

\section{Summary and Conclusions}

We have presented the results of a statistical characterization study of the abyssal hills formed by two adjacent intermediate spreading rate segments. The two most robust abyssal hill size estimates (RMS height $H$ and characteristic width $\lambda$ ), combined with magnetic and gravity data, were used to quantify the temporal evolution of this ridge crest system. This study documents a well-resolved negative correlation between abyssal hill size parameters and full spreading rates for the Pacific-Antarctic Ridge at $65^{\circ} \mathrm{S}$. Abyssal hills formed during slower spreading periods (ages $>8$ Ma; full rates $36-44 \mathrm{~mm} / \mathrm{yr}$ ) are $31-86 \%$ taller and $21->100 \%$ wider than hills created during the faster spreading interval (ages <4 Ma; full rates $52-63 \mathrm{~mm} / \mathrm{yr}$ ). We also show evidence for a well-resolved positive correlation between $H$ and $\lambda$ along flow lines, which is expected if abyssal hills are formed either by extensional tectonics or by volcanism. Such positive correlation is consistent with abyssal hills created at slow spreading ridges [Goff, 1992]. Flow line studies on abyssal hills are not available for fast spreading ridges.

Flow line variations in crustal thickness (inferred from the mantle Bouguer gravity) are small (0.1-0.4 km) when compared to $\sim 2-\mathrm{km}$ variations reported for the flanks of the Mid-Atlantic Ridge [Lin et al., 1992]. The correlation between abyssal hill size estimates and crustal thickness is low and, for the most part, insignificant along the flow lines for all subareas. The apparent decrease in crustal thickness by $\sim 0.5-0.7 \mathrm{~km}$ from north to south across the PFZ coincides with a statistically significant increase in the averaged $\lambda$ estimate for the past 12 m.y. A north to south increase in averaged $H$ estimate is only well-resolved for young ages ( $<4$ Ma).
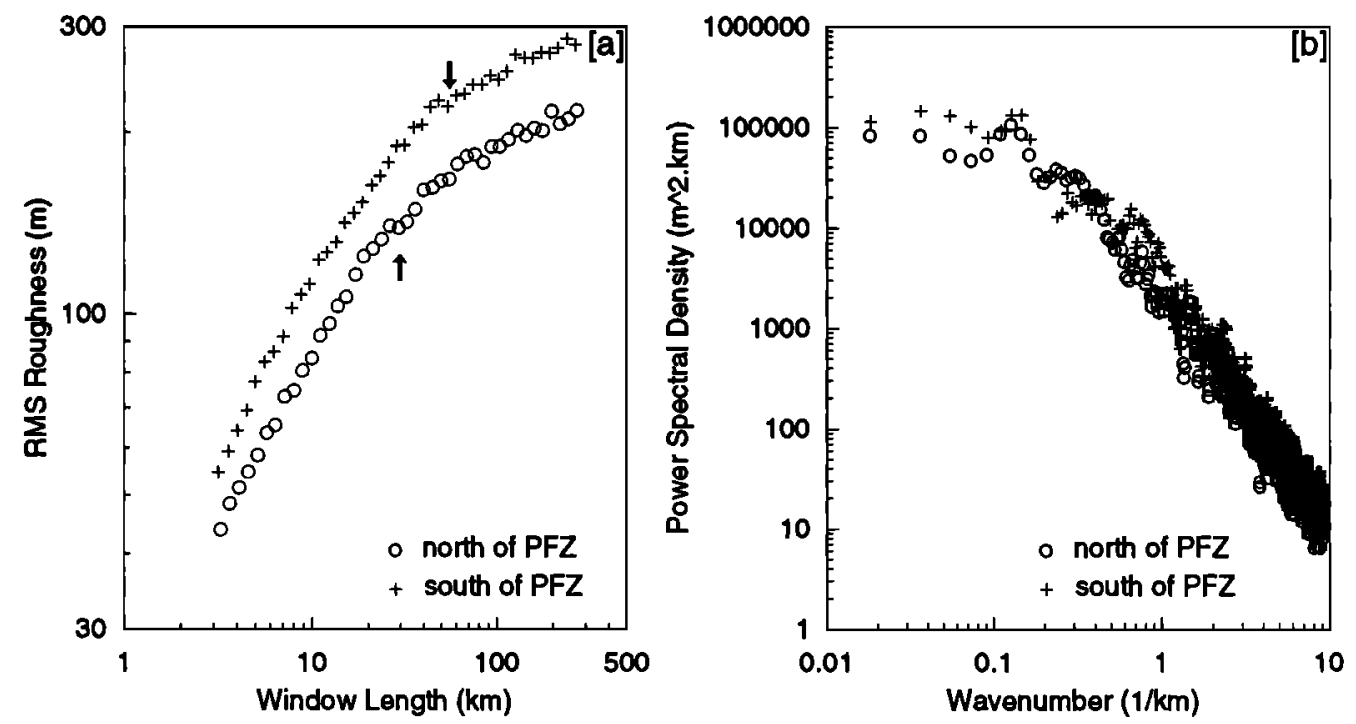

Figure 9. Analysis of residual flow lines profiles (thermal cooling curve removed) $\sim 1350 \mathrm{~km}$ long north and south of the PFZ. (a) Topographic roughness measurements against window length obtained using the roughness-length method [Malinverno, 1990]. The predicted transition from a power law regime to a flat line occurs at window lengths of $\sim 62 \mathrm{~km}$ south of the PFZ $\left(\alpha \sim 22 \mathrm{~km} ; T_{\varepsilon} \sim 5.6 \mathrm{~km}\right)$ and $\sim 31 \mathrm{~km}$ north of PFZ $\left(\alpha \sim 11 \mathrm{~km} ; T_{\&} \sim 2.1 \mathrm{~km}\right)$. (b) Power spectra of the two profiles. 
Variations in $H$ and $\lambda$ that cannot be explained in terms of either the spreading rate or crustal thickness effect include the following: (1) the anomalously large abyssal hills north of the PFZ for 4-6 Ma age crust; (2) abyssal hill size estimates for crustal ages greater than $8 \mathrm{Ma}$ are significantly higher for the Antarctic plate relative to the Pacific plate north of the PFZ; and (3) toward the segment ends, a $27-68 \%$ increase in abyssal hill height is observed for all subareas while either no significant changes (to the north of the PFZ) or up to a $40 \%$ decrease (to the south of the PFZ) in characteristic width estimates are found. These observations may reflect alongaxis changes in either the amount of extension (without a corresponding variation in the strength of the lithosphere) or in the relative contribution of volcanism to overall abyssal hill morphology.

The topographic roughness predictions due to normal faulting presented by Malinverno and Cowie [1993] provide a means of interpreting abyssal hill height and characteristic width characteristics in terms of lithospheric strength. Using their formulation for the dependence of the roughness due to normal faulting on profile length, it can be postulated that the flexural length scale for the southern segment over the past has been, on average, larger than for the northern segment (i.e., the lithosphere is stronger south of the fracture zone). This scenario is consistent with the current axial morphology and the decrease in crustal thickness from north to south across the PFZ.

Previous studies at slow spreading ridges suggest the presence of both crustal thickness and abyssal hill size asymmetries between inside and outside comer crust generated near a ridge discontinuity [e.g., Tucholke et al., 1992]. For the slower spreading intervals of this flow line corridor (age $>8 \mathrm{Ma}$ ) the observed abyssal hill size asymmetry seen is in the opposite sense to that predicted by differential crustal thickness; furthermore, there is no apparent asymmetry in crustal thickness. Conversely, for the faster spreading periods (crustal age $<4 \mathrm{Ma}$ ), some asymmetry in crustal structure exists (though variable and likely related to volcanic overprinting), but no asymmetry in abyssal hill morphology can be detected. In this aspect, abyssal hills within the study area are more consistent with those generated at fast spreading ridges (i.e., no systematic inside/outside corner asymmetry) rather than those generated at slow spreading ridges.

Acknowledgments. We wish to thank the captain and crew of the R/V Maurice Ewing for their dedication and hard work in collecting these data, S. O'Hara and D. Chayes for Hydrosweep data reduction and S. Tebbens, D. Mueller, B. O'Brien and M. Wilkinson for assistance at sea. A. Malinvemo provided valuable advice and a thoughtful review of this manuscript. We also thank $R$. Pockalny for a careful review. LDEO contribution 5235 . This research was supported by NSF grant OCE 91-03573.

\section{References}

Bicknell, J. D., J.-C. Sempere, K. C. Macdonald, and P. J. Fox, Tectonics of a fast spreading center: A Deep-Tow and Sea Beam survey on the East Pacific Rise at 19³0'S, Mar. Geophys. Res., 9, 25-45, 1987.

Cande, S. C., and D. V. Kent, A geomagnetic polarity time scale for the late Cretaceous and Cenozoic, J. Geophys. Res., 97, 13,917-13,951, 1992.

Cande, S. C., C. A. Raymond, W. F. Haxby, W. B. F. Ryan, S. Tebbens, S. O'Hara, D. Mueller, B. O'Brien, and W. Wilkinson, Preliminary results of a Hydrosweep swath bathymetry, magnetics and gravity survey of a Pacific-Antarctic Ridge FZ, Pan I: Plate kinematics, Eos Trans. AGU, 73(14), Spring Meeting suppl., 295, 1992.

Carbotte, S., and K. C. Macdonald, Comparison of sea floor tectonic fabric created at intermediate, fast, and ultra-fast spreading ridges, Eos, Trans. AGU, 72 (44), Fall Meeting suppl., 456, 1991.

Edwards, M. H., W. B. F. Ryan, and D. J. Fomari, A tectono-volcanic model for abyssal hill formation on the intermediate-fast spreading East Pacific Rise, Eos Trans. AGU, 73 (43), Fall Meeting suppl., 502, 1992.

Goff, J. A., A global and regional stochastic analysis of near-ridge abyssal hill morphology, J. Geophys. Res., 96, 21,713-21,737, 1991.

Goff, J. A., Quantitative characterization of abyssal hill morphology along flow lines in the Atlantic Ocean, J. Geophys. Res., 97, 9,1839,202, 1992.

Goff, J. A., and T. H. Jordan, Stochastic modeling of seafloor morphology: Inversion of Sea Beam data for second-order statistics, J. Geophys. Res., 93, 13,589-13,608, 1988.

Goff, J. A., M. C. Kleinrock, J. Lin, and B. E. Tucholke, Quantitative analysis of abyssal hill morphology within three segments: The west flank of the MAR $25^{\circ} 25^{\circ} \mathrm{N}-27^{\circ} 10^{\circ} \mathrm{N}$ and 0-30 Ma, Eos Trans., AGU, 73(43), Fall Meeting suppl., 538, 1992.

Goff, J. A. , A. Malinvemo, D. J. Fomari, and J. R. Cochran, Abyssal hill segmentation: Quantitative analysis of the East Pacific Rise Flanks 7'S-9S, J. Geophys. Res., 98, 13,851-13,862, 1993.

Harrison, C. G., and L. Stieltjes, Faulting within the median valley, Tectonophysics, 38, 137-144, 1977.

Haxby, W. F., C. A. Raymond, S. C. Cande, W. B. F. Ryan, S. Tebbens, S. O'Hara, D. Mueller, B. O'Brien, and W. Wilkinson, Preliminary results of a Hydrosweep swath bathymetry, magnetics and gravity survey of a Pacific-Antarctic ridge FZ, Part II: Crustal Structure, Eos Trans. AGU, 73(14), Spring Meeting suppl., 278, 1992.

Haxby, W.F., A. Macario, and W.B.F. Ryan, A movie of PacificAntarctic seafloor spreading, EOS Trans. AGU, 74(43), Fall Meeting suppl., 687, 1993.

Hayes, D. E., and K. A. Kane, The dependence of seafloor relief on spreading rate, Geophys. Res. Lelt., 18, 1,425-1,428, 1991.

Kappel, E. S., and W. B. F. Ryan, Volcanic episodicity and a non-steady state relief valley along Northeast Pacific spreading centers: Evidences from Sea Marc I, J. Geophys. Res., 91, 13925-13940, 1986.

Keeley , C., W. B. F. Ryan, L. Pratson and W. F. Haxby, Ridge flank flooding from a segment midpoint revealed from Hydrosweep data: East Pacific Rise 7'S to 9'S, Eos, Trans. AGU, 73(43), Fall Meeting suppl., 554, 1992.

Kong, L. S. L., R. S. Dietrick, P. J. Fox, L. A. Mayer, and W. B. F. Ryan, The morphology and tectonics of the Mark area from Sea Beam and Sea MARC I observations (Mid-Atlantic Ridge $23^{\circ} \mathrm{N}$ ), Mar. Geophys. Res., 10, 59-80, 1988.

Lewis, B. T. R., Periodicities in volcanism and longitudinal magma flow, on the East Pacific Rise at $23^{\circ}$, Geophys. Res. Lett., 6, 753-756, 1979.

Lin, J. , B. E. Tucholke, M. C. Kleinrock, and J. A. Goff, Variations in crustal faulting and magmatic accretion along the Mid-Atlantic Ridge and off-axis: Results from the western flank of the MAR at 25-27\% Eos Trans. AGU, 73(43), Fall Meeting suppl., 538, 1992.

Lonsdale, P., Structural geomorphology of a fast spreading rise crest: The East Pacific Rise near 32S, Mar. Geophys. Res., 3, 251-293, 1977.

Macdonald, K. C. and T. Atwater, Evolution of rifted ocean ridges, Earth Planet. Sci. Lett., 39, 319-327, 1978.

Macdonald, K. C., Mid-ocean ridges: Finite scale tectonic, volcanic and hydrothermal processes within the plate boundary zone, Annu. Rev Earth Planet. Sci., 10, 155-190, 1982.

Malinverno, A., A simple method to estimate the fractal dimension of a self-affine series, Geophys. Res. Lett., 17, 1953-1956, 1990.

Malinverno, A., Inverse square-root dependence of mid-ocean ridge flank roughness on spreading rate, Nature, 352, 58-60, 1991.

Malinverno, A., Transition between a valley and a high at the axis of mid-ocean ridges, Geology, 21, 639-642, 1993. 
Malinvemo, A., and P. A. Cowie, Normal faulting and the topographic roughness of mid-ocean ridge flanks, J. Geophys. Res., 98, 17921 17935, 1993.

Marks, K. M., and J. M. Stock, Variations in the ridge morphology and depth-age relationships on the Pacific-Antarctic Ridge, J. Geophys. Res., 99, 531-541, 1994.

Menard, H. W., Seafloor spreading, topography and the second layer, Science, 157, 923-924, 1967.

Mutter, J. C., and J. A. Karson, Structural processes at slow spreading ridges, Science, 257, 627-634, 1992.

Parker, R. L., The rapid calculation of potential anomalies, Geophys. $J$. R. Astron. Soc. , 31, 447-455, 1973.

Phipps Morgan, J., and Y. J. Chen, The genesis of oceanic crust: Magma injection, hydrothermal circulation and crustal flow, J. Geophys. Res., 98, 6283-6298, 1993a.

Phipps Morgan, J,, and Y. J. Chen, Dependence of ridge-axis morphology on magma supply and spreading rate, Nature, 364, 706$708,1993 b$.

Pockalny, R. A., R. S. Detrick and P. J. Fox, Morphology and tectonics of the Kane Transform from Sea Beam bathymetry data, J. Geophys. Res., 93, 3,179-3,193, 1988.

Press, W. H., B. P. Flannery, S. A. Teukolsky, and W. T. Veuerling, Numerical Recipes in C, 735 pp., Cambridge University Press, New York, 1991.

Rea, D. K., Model for the formation of topographic features on the East Pacific Rise crest, Geology, 3, 77-80, 1975.

Ryan, W. B. F., C. A. Raymond, S. C. Cande, W. F. Haxby, S. Tebbens, S. O'Hara, D. Mueller, B. O'Brien and M. Wilkinson, Documentation of ridge-axis jumps on the Pacific-Antarctic spreading center, Eos Trans. $A G U, 73(14)$, Spring Meeting suppl., 295, 1992.
Small, C., and D. T. Sandwell, An analysis of ridge-axis gravity roughness and spreading rate, J. Geophys. Res., 97, 3235-3245, 1989.

Smith, D. K., and J. Cann, Hundreds of small volcanoes on the median valley floor of the Mid-Atlantic Ridge at $24^{\circ}-30^{\circ} \mathrm{N}$, Nature, 348, 152 $155,1990$.

Smith, D. K., and T. H. Jordan, Seamount statistics in the Pacific Ocean, J. Geophys. Res., 93, 2899-2917, 1988.

Tucholke, B. E., and H. Shouten, Kane Fracture Zone, Mar. Geophys. Res. 10, 1-39, 1988.

Tucholke, B. E., J. Lin and M. C.. Kleinrock, Crustal structures of spreading segments on the westem flank of the Mid-Atlantic Ridge at $25^{\circ} 25 \mathrm{~N}$ to $27^{\circ} 10 \mathrm{~N}$, Eos Trans., $A G U$, 73(43), Fall Meeting suppl., $537,1992$.

S. C. Cande, Geological Research Division, Scripps Institution of Oceanography, La Jolla, CA 92093-0215. (e-mail: cande@gauss.ucsd.edu)

J. A. Goff, University of Texas Institute for Geophysics, 8701 Mopac Blvd, Austin, TX 78759-8397. (e-mail: goff@utig.ig.utexas.edu)

W. F. Haxby, A. Macario and W. B. F. Ryan, Lamont-Doherty Earth Observatory, Palisades, NY 10964-800. (e-mail: bill@lamont.1deo.columbia.edu; ana@lamont.ldeo.columbia.edu; billr@lamont.ldeo.columbia.edu)

C. A. Raymond, Jet Propulsion Laboratory, 4800 Oak Grove Dr., MS 183-501, Pasadena, CA 91109. (e-mail: car@orion.jpl.nasa.gov)

(Received November 11, 1993; revised May 13, 1994; accepted May 18, 1994.) 